\title{
Fresh and Hardened State of Polymer Modified Concrete and Mortars - A Review
}

\author{
Nurul Nadrah Aqilah Tukimat ${ }^{1}$, Noor Nabilah Sarbini ${ }^{2, *}$, Izni Syahrizal Ibrahim², Chau \\ Khun $\mathrm{Ma}^{2}$, and Khairunisa Mutusamy ${ }^{1}$ \\ ${ }^{1}$ Faculty of Civil Engineering and Earth Resources, Universiti Malaysia Pahang, 26300 Gambang, \\ Pahang, Malaysia \\ ${ }^{2}$ Department of Structures and Materials, Faculty of Civil Engineering, Universiti Teknologi \\ Malaysia, 81310 Johor Bahru, Johor, Malaysia
}

\begin{abstract}
Polymer modified concrete or mortar is an alternative to the advancement of long serving civil engineering material - mortar and concrete. The excellence and promising benefits of modified composites have led to numerous progressive studies of its application. This paper presented a critical review from previous research on the polymer modified concrete and mortar. Both fresh and hardened state behaviours were reviewed as they are important for the development of excellent engineering material. Most of the applications of polymer modified concrete and mortar can be seen in diverse types of polymer such as latex, epoxy and emulsion. The utilization of each type of polymers resulted in different characteristics of composite concrete or mortar. Such applications have contributed to the improvement in terms of workability and mechanical strength, especially at higher grade of composite strength of concrete material.
\end{abstract}

\section{Introduction}

The application of polymer modified concrete has been started since a few centuries back. There are three types of polymer concrete, which are polymer concrete, polymer modified concrete and polymer impregnated concrete [1-4]. Polymer concrete can be defined as a composite material with its binder made of synthetic organic polymer, while the polymermodified concrete consists of the combination of cement and polymer in certain proportion as binder [1]. The preparation for polymer type concrete, especially for polymer concrete and polymer modified concrete, is by mixing the polymer or monomer (in the form of powder or liquid) with aggregates for polymer concrete, and with the addition of cement for polymer modified concrete [2]. On the other hand, polymer impregnated concrete is a special concrete with its preparation needing the injection of low-density monomer into hydrated Portland cement, followed by the thermal catalytic polymerization process [5]. The polymerization process will normally occur during the mixing of concrete.

The use of polymer modified concrete and mortar as construction material might drastically increase the cost of a project; therefore it should be used for special conditions

* Corresponding author: noornabilah@utm.my 
or occasions. The benefits of polymer modified concrete and mortar include superior properties, low labour cost and low energy requirements [1]. In details, the advantages of using polymer modified concrete and mortar have disguised its higher cost by providing a construction project with fast curing, excellent strength, durability, excellent damping properties and excellent elastic moduli [1]. These advantages have improved the reliance on conventional construction material, which has disadvantages such as delayed hardening, low tensile strength, large drying shrinkage and low chemical resistance [2].

Recently, the application of polymer in civil engineering fields is expanding. In all of its applications reported on its benefits of repair system for deteriorated reinforced concrete structures, strengthening or retrofitting of existing reinforced concrete structures, adhesive or bonding agents for delamination method, liquid-applied membrane waterproofing system and high grade redispersible polymer powders [6]. This has promoted a very broad alternative in repairing works in a row with other methods of strapping and conventional grouting [7-8]. Besides, it can also be applied as structural members such as flooring and roofing systems due to the development of the polymer itself, which can sustain stresses for heavier role purposes. On the other hand, epoxy latex inside a polymer concrete promises high adhesion, low setting time, post-setting shrinkage, creep resistance, higher acid and alkali resistance [1]. Epoxy is the most expensive polymer material, thus, it is normally used for special applications, such as those needing excellent bonding, or specific to repair works.

This paper reviews the behaviour of polymer modified concrete and mortars during the fresh and hardened state conditions. As in the plain concrete behaviour, the fresh state condition is focussing in the consistency and workability of the composite. Meanwhile, the hardened state condition focused on the mechanical strength of such composite.

\section{Fresh state of polymer modified cement}

Aggarwal [9] studied the effect of epoxy and acrylic emulsion to water to cement ratio of polymer modified mortar. The epoxy was prepared from bisphenol-A and amino-amide. The selected polymer to cement ratio varied from $10 \%, 20 \%$ and $30 \%$, for both polymers. Through their study, it was found that acrylic decreased water requirement compared to epoxy, and reduced water to cement ratio with further amount of polymer to cement ratio. This is mainly due to the characteristics of polymer, in this case acrylic, which produces higher boundary surfactants due to low surface tension in a composite. This result in higher workability or better flow condition for acrylic compared to epoxy and normal mortar (at the same water content).

The flowability characteristics of polymer type mortar were also studied by Subham and Sing [10]. Two types of polymer were used in their work; styrene-butadine-rubber latex (SBR) and vinyl acetate/ethylene (VAE), which were added to mortar at 5\%,10\%, 15\% and $20 \%$. A comparison between the two polymers showed that SBR exhibited higher workability compared to VAE. Additionally, the comparison between both polymers with conventional mortar still showed that the polymers had improved the workability. The higher percentage replacement (20\%) SBR had improved the workability of polymer modified mortar by $100 \%$ from the flow value. This is due to the ability of SBR to improve the flowability of composite through excellent ball bearing action.

El-Dakroury [11] studied the inclusion of polyvinyl alcohol (PVA) with the addition of silica fume to the polymer modified mortar. The silica fume percentage was fixed at $10 \%$ cement replacement, while the polymer content of PVA varied from 3\%, 5\%, 7\% and 10\% by the weight of cement. The fresh condition of the polymer modified mortar showed that higher addition of PVA retarded the setting time of the polymer modified mortar. This is mainly due to the inclusion of PVA causing limited dissolved $\mathrm{Ca}^{2+}$ ion to produce $\mathrm{Ca}(\mathrm{OH})_{2}$ 
into the solution. Besides, the inclusion of PVA decreased the water absorption of the polymer modified mortar at higher percentage of replacement. This observation was also previously discovered by Barluenga [12], whereby SBR inclusion retarded the initial and final time setting of the composite at higher addition of cement replacement.

The observations are aligned to the one reported by Zivica [13] and Ohama [2]. They stated that the use of polymer modified cement in concrete or mortar causes delayed setting time compared to the conventional one, due to increased polymer to cement ratio. However, this delay does not cause any difficulty or inconvenience to its application [2]. The main reason for the delay is inhibition of cement hydration due to the adsorption of surfactants. Although the flowability of the polymer modified cement is higher compared to the conventional cement, the resistance of the composite to bleeding and segregation is excellent. This benefit is due to the properties of most of the polymer, which are having airentraining and water-reducing capabilities [2].

Water-soluble polymers help in improving the dry-out phenomena of polymer concrete. The dry-out phenomena from water-soluble polymer improved the viscosity of the water phase in polymer modified cement [2]. The viscosity improves by the existence of a very thin and water-impervious film in PMC. Therefore, water-soluble polymer is normally used in polymer mortar, especially as a binder material. Other previous works studied the effect of cellulose ether (CE) and polyvinyl alcohol (PVA) addition to mortar. Three major observations were made based on; (i) the mobility of pore water and polymers, (ii) volumetric changes, and (iii) reinitiated hydration of the cement. Through their research, three mechanisms that affect the composite are cement hydration, mortar volume change and reversible swelling of the latex films [14-15].

\section{Hardened state of polymer modified cement: Mechanical strength and durability}

The hardening process for polymer concrete involves the manipulation of polymerization process of the polymers or monomers inside the composite. However, polymer modified concrete has a very complicated relationship as both hydration and polymerization processes will occur inside the composite for the hardening process. Wagner [16] discovered that the cement hydration process precedes the polymerization process for polymer modified concrete, and thus, it should always be ensured that both processes proceed well to form an excellent monolithic composite.

Ohama [2] also reported that the inclusion of polymer latex to modified cement will result in less or no improvement in compressive strength compared to that of the conventional composite. However, he also reported that significant improvement due to such addition can be seen in terms of the flexural or tensile strength of the new composite. In general, there are various factors that can contribute to the strength of the composite. The main factors include the characteristics of polymer and other compositions within the new composite, the mixing proportion of polymer to cement ratio, water-cement ratio, bindervoid ratio and the curing method. Table 1 summarizes the findings of previous research on the compressive strength of polymer modified cement. In general, the polymer content that have been used by researchers varied, but limited to less than $25 \%$ of cement replacement. The research which reported no improvement on compressive strength are those of Xin [17], Parghi and Shahria Alam [18], and Subham and Sing [10].

To that matter, the research works from Xin [17] and Subham and Sing [10] showed that both normal and high strength concretes gave similar observation due to the addition of polymer. Both used styrene-butadine rubber latex at 5, 10, 15 and $20 \%$ polymer content, and showed no improvement in the compressive strength of the polymer modified mortar. The non-improvement can be seen when, the compressive strength have dropped by a 
maximum of $67 \%$ for $20 \%$ polymer content in the study by Xin [17]; while for Subham and Singh [10], a maximum of $65 \%$ drop was also observed for $20 \%$ polymer content. Even though the compressive strength dropped, the workability improved due to higher addition of polymer content. This was also discovered by Xin [17] although they included $0.1 \%$ polyester fibre into the modified mortar.

On the other hand, Bhikshma [19] studied styrene-butadine rubber latex polymer concrete. A remarkable improvement was seen for normal and high strength polymer modified concrete. They reported that, at $10 \%$ polymer content, the improvement was at a maximum of $50 \%$ for normal strength concrete when compared to that of conventional, and $21 \%$ for high strength concrete. This shows that the improvement was significant when polymer was used to modify cement inside concrete. Other work from Oussama [20] reported an improvement of up to $207 \%$ for $16 \%$ polymer content in a modified concrete. The type of polymer that they used was bishenol-A epoxy resin. The significant improvement in compressive strength was also previously reported by Golestaneh [21]. They reported that the improvement was up to $18 \%$ for $15 \%$ polymer content using bishenol-A epoxy resin in polymer modified concrete with the addition of silica fume as filler.

The flexural strength of polymer modified cement was studied by many researchers as shown in Table 2. Some reported no improvement [17], while others reported marginal improvement [18-19, 21-22], compared to conventional cement. Basically, there are various factors influencing the strength of polymer modified cement. One of the factors is the type and amount of surfactants and antifoamers, and monomer ratio in a copolymer. Wang [22] discovered that the flexural strength of polymer modified mortar (styrene-butadine rubber latex) did not improve for more than $10 \%$ polymer content. More than this, polymer content is believed to have thickened the composite while reduced the workability and dropped the strength. Besides, Wang [22] also found that different curing methods severely affected the strength properties. From their work, it was found that the best type of curing method was the mixed method (wet and dry air curing), compared to wet curing alone [22].

In addition, concrete strength also affects the strength of the new polymer modified cement. This was discovered by Bhikshma [19], which found significant improvement on flexural strength for normal grade concrete, compared to high strength concrete. This scenario is closely related to the condition of the concrete. High strength concrete has the characteristic of porosity, compared to normal strength concrete. The porosity caused the addition of polymer does not result to any significant improvement in strength. However, this situation can be improved by using microfiller. This has been addressed previously [2325]. Microfiller is a very fine powder, which can fill the gaps between aggregates and polymer; such as fly ash and silica fume [4]. When it is added to mortar or concrete, it will fill the gaps between other components and helps to produce denser material.

Despite having uncertainty on the mechanical strengths of polymer modified cement, studies on long term performance by several researchers showed remarkable improvement. Barluenga [12] reported compressive strength improvement of up to 56 days aged. While, optimum polymer content at $10 \%$ have showed remarkable improvement of up to $20 \%$. Later, Xin [17] also studied the effect of polymer content on compressive strength for polymer modified mortar up to 90 days. The comparison showed strength improvement between 28 days and 90 days, which was more than $50 \%$ for maximum polymer content of $20 \%$. 
Table 1. Compressive strength of polymer modified concrete and mortars

\begin{tabular}{|c|c|c|c|c|c|}
\hline \multirow[b]{2}{*}{ Ref } & \multirow[b]{2}{*}{$\begin{array}{l}\text { Types of } \\
\text { polymer }\end{array}$} & \multicolumn{4}{|c|}{ Compressive strength at 28 days } \\
\hline & & $\begin{array}{l}\text { Control } \\
\text { strength } \\
\left(\mathbf{N} / \mathbf{m m}^{2}\right)\end{array}$ & $\begin{array}{c}\text { Polymer } \\
\text { content }(\%)\end{array}$ & $\begin{array}{c}\text { Compressive } \\
\text { strength }\left(\mathrm{N} / \mathbf{m m}^{2}\right)\end{array}$ & $\begin{array}{l}\text { Difference to } \\
\text { control }( \pm \%)\end{array}$ \\
\hline \multirow{4}{*}{ [10] } & \multirow{4}{*}{$\begin{array}{l}\text { Styrene-butadine } \\
\text { rubber latex }\end{array}$} & \multirow{4}{*}{23} & 5 & 20 & -13 \\
\hline & & & 10 & 14 & -39 \\
\hline & & & 15 & 11 & -52 \\
\hline & & & 20 & 8 & -65 \\
\hline \multirow{4}{*}{ [11] } & \multirow{4}{*}{ Polyvinyl alcohol } & \multirow{4}{*}{70} & 3 & 72 & 3 \\
\hline & & & 5 & 90 & 29 \\
\hline & & & 7 & 90 & 29 \\
\hline & & & 10 & 100 & 43 \\
\hline \multirow{4}{*}{ [17] } & \multirow{4}{*}{$\begin{array}{l}\text { Styrene-butadine } \\
\text { rubber latex }\end{array}$} & \multirow{4}{*}{55} & 5 & 27 & -51 \\
\hline & & & 10 & 28 & -49 \\
\hline & & & 15 & 31 & -44 \\
\hline & & & 20 & 18 & -67 \\
\hline \multirow{4}{*}{ [18] } & \multirow{4}{*}{ Polyacrylic esther } & \multirow{4}{*}{30} & 5 & 27.8 & -12 \\
\hline & & & 10 & 26.5 & -17 \\
\hline & & & 15 & 25 & -24 \\
\hline & & & 20 & 22.7 & -33 \\
\hline \multirow{6}{*}{ [19] } & \multirow{6}{*}{$\begin{array}{l}\text { Styrene-butadine } \\
\text { rubber latex }\end{array}$} & \multirow{3}{*}{30} & 5 & 35 & 17 \\
\hline & & & 7.5 & 40 & 33 \\
\hline & & & 10 & 45 & 50 \\
\hline & & \multirow{3}{*}{72} & 5 & 75 & 7 \\
\hline & & & 7.5 & 80 & 14 \\
\hline & & & 10 & 85 & 21 \\
\hline \multirow{4}{*}{ [20] } & \multirow{4}{*}{$\begin{array}{l}\text { Bisphenol-A as } \\
\text { epoxy }\end{array}$} & \multirow{4}{*}{30} & 6 & 25 & -17 \\
\hline & & & 9 & 36 & 20 \\
\hline & & & 13 & 85 & 183 \\
\hline & & & 16 & 92 & 207 \\
\hline \multirow{3}{*}{ [21] } & \multirow{3}{*}{$\begin{array}{c}\text { Bisphenol-A as } \\
\text { epoxy }\end{array}$} & & 10 & 73 & 0 \\
\hline & & 73 & 15 & 107 & 18 \\
\hline & & & 20 & 91 & 0 \\
\hline & & & 5 & 34 & 21 \\
\hline & Styrene-acrylic & 28 & 10 & 37 & 32 \\
\hline [22] & polymer & 28 & 15 & 40 & 43 \\
\hline & & & 20 & 29 & 4 \\
\hline & & & 9 & 36 & 0 \\
\hline & bonding agent for & 36 & 12 & 38 & 6 \\
\hline & concrete & & 15 & 22 & -42 \\
\hline$[26$ & Multipurpose & & 9 & 63 & 0 \\
\hline [20] & bonding agent for & 63 & 12 & 72 & 14 \\
\hline & grout & & 15 & 64 & -11 \\
\hline & & & 9 & 55 & 0 \\
\hline & Polyesther resin & 55 & 12 & 72 & 31 \\
\hline & & & 15 & 63 & -13 \\
\hline
\end{tabular}


Table 2. Flexural strength of polymer modified concrete and mortars

\begin{tabular}{|c|c|c|c|c|}
\hline \multirow{2}{*}{ Ref } & \multirow{2}{*}{$\begin{array}{l}\text { Types of } \\
\text { polymer }\end{array}$} & \multirow{2}{*}{$\begin{array}{c}\text { Polymer } \\
\text { content }(\%)\end{array}$} & \multicolumn{2}{|c|}{ Flexural strength } \\
\hline & & & at 28 days $\left(\mathrm{N} / \mathrm{mm}^{2}\right)$ & Difference to control $( \pm \%)$ \\
\hline \multirow{5}{*}[12]{} & \multirow{5}{*}{$\begin{array}{l}\text { Styrene- } \\
\text { butadine } \\
\text { rubber latex }\end{array}$} & 5 & 5.3 & 6 \\
\hline & & 10 & 5.35 & 7 \\
\hline & & 15 & 4.9 & -2 \\
\hline & & 20 & 4.25 & -15 \\
\hline & & 25 & 5.3 & 6 \\
\hline \multirow{4}{*}{ [17] } & \multirow{4}{*}{$\begin{array}{c}\text { Styrene- } \\
\text { butadine } \\
\text { rubber latex }\end{array}$} & 5 & 7 & -7 \\
\hline & & 10 & 7.5 & -9 \\
\hline & & 15 & 7.5 & -9 \\
\hline & & 20 & 7.55 & -8 \\
\hline \multirow{4}{*}{ [18] } & \multirow{4}{*}{$\begin{array}{l}\text { Polyacrylic } \\
\text { esther }\end{array}$} & 5 & 5.32 & 33 \\
\hline & & 10 & 5.47 & 37 \\
\hline & & 15 & 5.59 & 40 \\
\hline & & 20 & 4.71 & 18 \\
\hline \multirow{6}{*}{ [19] } & \multirow{6}{*}{$\begin{array}{l}\text { Styrene- } \\
\text { butadine } \\
\text { rubber latex }\end{array}$} & 5 & 5.5 & 10 \\
\hline & & 7.5 & 6 & 20 \\
\hline & & 10 & 6.3 & 26 \\
\hline & & 5 & 8 & 14 \\
\hline & & 7.5 & 8.2 & 17 \\
\hline & & 10 & 8.2 & 17 \\
\hline \multirow{3}{*}{ [21] } & \multirow{3}{*}{$\begin{array}{l}\text { Bisphenol-A } \\
\text { as epoxy }\end{array}$} & 10 & 14.3 & 0 \\
\hline & & 15 & 22.5 & 57 \\
\hline & & 20 & 10.13 & -29 \\
\hline \multirow{4}{*}{ [22] } & \multirow{4}{*}{$\begin{array}{l}\text { Styrene- } \\
\text { butadine } \\
\text { rubber latex }\end{array}$} & 5 & 8.2 & 26 \\
\hline & & 10 & 8.4 & 29 \\
\hline & & 15 & 8.4 & 29 \\
\hline & & 20 & 8.6 & 32 \\
\hline \multirow{4}{*}{ [27] } & \multirow{4}{*}{$\begin{array}{l}\text { Styrene- } \\
\text { acrylic } \\
\text { polymer }\end{array}$} & 5 & 4.8 & 50 \\
\hline & & 10 & 5.4 & 69 \\
\hline & & 15 & 5.6 & 75 \\
\hline & & 20 & 4.2 & 31 \\
\hline
\end{tabular}

The durability aspect of polymer modified mortar beam was studied by Bureau [28]. An aqueous emulsion of styrene-butadine polymer at 5, 7.5, 10, 12.5, 15 and 20\% polymer contents were studied for their durability as a polymer modified mortar. Two main observations made were; less than $10 \%$ polymer content influenced the micro-cracks initiated in a composite, while more than $12.5 \%$ polymer content consolidated the composite and caused better viscous dissipation of stress redistribution when micro-cracks occur. Later, Pascal [29] also reported on the durability aspect of polymer modified mortar beam. They concluded that the main reason for increased bending capacity in a beam with higher polymer content is due to the continuous polymer network formation [29]. In that condition, the cement hydration process or compressive strength of the mortar had less influence on the bending capacity.

The styrene-butadine polymer network formation was studied by Yang [30]. Through the electro-migration test on a specimen, it was found that the polymer improved the composite against chloride penetration and its permeability. Besides, its network formation produced stiffer composite which led to decreased electric capacitance through the specimen. In general, the addition of polymer altered the internal microstructure and 
improved through the existence of stronger binding network between aggregate and polymer [30]. Next, this also contributed to reduce the portlandite content while mitigated the carbonation of such composite, and facilitated the chloride binding by the formation of calcium aluminate trisulfate hydrate [30].

The durability of styrene-butadine latex modified concrete at $15 \%$ polymer content was studied previously by Shaker [31]. A series of tests including water penetration, sorptivity, abrasion resistance and corrosion resistance were conducted as early at 28 days and up to a long term period of 12 months. Amongst their findings was that polymer modified concrete has the characteristic of denser microstructure due to smaller pores and excellent bonding between inside elements. This characteristic benefits the durability of the composite and gives better water tightness and higher resistance to abrasion and corrosion. This observation was applicable for both short term and long term periods for the specimens.

Redispersible polymer powders (RPW) is added during a dry mixed with other cement and aggregates components, followed by the addition of water [2]. The emulsified RPW will form during wet mixing (with during this time RPW will act like polymer latex). The advantages of using RPW are seen in improving the tensile strength of hardened mortar, and providing flexibility to the inside components [14]. Different types of polymer will give different characteristics. However, the weakness of adding RPW is obvious in terms of the efflorescence of the polymer concrete. Based on a previous study by Silva, the efflorescence process can occur when the acetate polymer undergoes alkaline hydrolysis due to the addition of water [32]. The product of alkaline reacts with $\mathrm{Ca}^{2+}$ ion from the cement to form calcium acetate, which is an organic salt causing efflorescence.

On the other hand, Zhu [33] studied the effect of adding vinyl acetate copolymer (VAC) and vinyl chloride terpolymer (VCT) to polymer modified mortar. The addition of $10 \%$ of VAC and VCT into polymer modified mortar prolonged the efflorescence time on the surface of the mortar specimen. Extremely, the use of VAC exacerbated the efflorescence of hardened mortar, while VCT exacerbated the efflorescence of fresh mortar. The observation concluded from the research was that VAC increases the soluble salts in hardened mortar and creates larger pores on the surface of the specimen. This condition has promoted the migration of inner salts to outer surface, and then caused the efflorescence. Meanwhile, VCT is a polymer which easily dissolves in the surface water and causes the efflorescence process to initiate during the fresh mortar state. This causes less $\mathrm{Ca}^{2+}$ ion being produced at later age and helps to prohibit the migration of $\mathrm{K}^{+}$and $\mathrm{Na}^{+}$ions, unlike VAC [33].

\section{Recent innovation of polymer modified cement}

The utilization of polymer waste micronized poly ethylene vinyl acetate (EVA) in mortar was studied by Brancher [34]. Though the compressive strength decreased due to the application, EVA waste contributed to producing more lightweight floor. This lightweight characteristic is due to the rises in void index through the use of EVA waste. Besides, this also contributed to noise attenuation transmitted through the floors and offer better acoustic comfort for residents if used inside a building.

Barbutta [35] reported different types of wastes that have been added as aggregates in polymer modified concrete. A certain proportion of argillaceous, calcareous, marble and fly ashes waste aggregates were added to $12.4 \%$ polymer content of epoxy resin with hardener. Scanning electron microscopy analysis showed that homogeneous composite was obtained for polymer modified concrete with calcareous and fly ash, however, nonhomogenous composite was obtained from composite with argillaceous and marble wastes. The homogeneous polymer modified concrete with added calcareous and fly ash resulted in increased mechanical strength for the composite. Besides, through the observation, when 
using the wastes, the reduction in resin usage in a composite is possible without sacrificing its mechanical strength performance [35]. Other than that, properties of certain waste materials such as good thermal insulation as reported by Aminudin [36] may lead to other attractive research in mixing the waste into the polymer concrete or mortar.

The inclusion of discrete fibre reinforcement inside polymer cement is not new and has been addressed before [2]. However, the research and innovation focus in this work have just expanded recently. Kumar and Bari [37] reported that the used of basalt fibre to reinforce polymer modified concrete is possible and could produce excellent composite. The benefits and advantages of basalt fibre such as high tensile strength, non-corrosive, resistance to abrasion, light weight and higher chemical resistance can improve the efficiency of polymer modified concrete [37]. As previously mentioned, the application of wastes in polymer modified cement, basalt fibre shares the same mission in saving the world. The used of environmentally friendly materials and recycled materials could benefit mankind and optimize the material itself. Other recent work had also reported on the use of natural polymer modified cement [38-41]. The efforts of using any environmentally friendly material will benefit the world by sustaining civilization without sacrificing natural sources.

\section{Conclusion}

In conclusion, polymer modified concrete and mortars with different types of polymer will possess different characteristics during their fresh and hardened states. Most of the works reported on the enhancement of workability during the fresh state and promising strength at higher strength grade. The characteristics of polymer modified concrete and mortars such as high performance, effective adhesive, multi-functional and widely market available cause its usage to be more favourable. The current application with the incorporation of environmental friendly and natural sources as part of the composition shows a good sign of polymer innovation.

The authors would like to acknowledge Universiti Malaysia Pahang and Universiti Teknologi Malaysia and thankful to all personnel that contribute to this paper.

\section{References}

[1] O. Figovsky and D. Beilin, Advanced polymer concretes and compounds, CRC Press, Taylor \& Francis Group, Boca Raton, (2014)

[2] Y. Ohama, Handbook of polymer-modified concrete and mortars, Noyes Publications, Park Ridge, New Jersey, USA, (1995)

[3] S.R. Bothra and Y. M. Ghugal, Polymer-Modified concrete: Review, Int. J. of Research in Engineering and Technology, 4(4), 845-848, (2015)

[4] K.T. Varughese and B.K. Chaturvedi, Fly Ash as fine aggregate in polyester based polymer concrete, Cement and Concrete Composites, 18(2), 105-108, (1996)

[5] A.S. Momtazi, R.K. Khoshbijari and S.S. Mogharab, Polymers in concrete: Applications and specifications, European Online J. of Natural and Social Sciences, Special Issue on New Trends in Architecture, Civil Engineering and Urban Studies, 3(3), 62-72, (2015)

[6] M.A. R.Bhutta and Y.Ohama, Recent status of research and development of concretepolymer composites in Japan, Concrete Research Letters, 1(4), 125-130, (2010)

[7] C.K. Ma, A.Z. Awang, W. Omar, M. Liang, J. Siow-Wei and M. Azimi, Flexural capacity enhancement of rectangular high-strength concrete columns confined with 
post-tensioned steel straps: Experimental investigation and analytical modeling, Structural concrete, 17(4), 668-676, (2016)

[8] C.K. Ma, A.Z. Awang, R. Garcia, W. Omar and K. Pilakoutas, Behaviour of over-reinforced high-strength concrete beams confined with post-tensioned steel straps-an experimental investigation, Structural Concrete, 17(5), 768-777, (2016)

[9] L.K. Aggarwal, P.C. Thapliyal and S.R. Karade, Properties of polymer-modified mortars using epoxy and acrylic emulsions, Construction and Building Materials, 21(2), 379-383, (2007)

[10] P. Subham and Singh, Enhancement of proeperties polymer modified ferrocement, Int. J. of Recent Development in Engineering and Technology, 4(8), 19-23, (2015)

[11] A. M. El-Dakroury, Mechanical and chemical properties of polyvinyl alcohol modified cement mortar with silica fume used as matrix including radioactive waste, Arab J. of Nuclear Science and Applications, 47(2), 44-53, (2013)

[12] G. Barluenga and F. Hernandez-Olivares, SBR latex modified mortar rheology and mechanical behaviour, Cement and Concrete Research, 34(3), 527-535, (2004)

[13] V. Zivica, The properties of cement paste with admixture of polyvinyl acetate emulsion, Bulletin RILEM, 28, 121-128, (1965)

[14] A. Jenni, L. Holzer, R. Zurbriggen and M. Herwegh, Influence of polymers on microstructure and adhesive strength of cementitious tile adhesive mortars, Cement and Concrete Research, 35(1), 35-50, (2005)

[15] A. Jenni, R. Zurbriggen, L. Holzer, and M. Herwegh, Changes in microstructures and physical properties of polymer-modified mortars during wet storage, Cement and Concrete Research, 36(1), 79-90, (2006)

[16] H.B. Wagner, Polymer-Modified hydraulic cements, industrial and engineering chemstry, Product Research and Development, 4(3), 191-196, (1965)

[17] D. Xin, Z. Xinping, C. Hanlin, W. Dingpeng, and Y. Wei, Mechanical properties of polyester fiber and sbr latex compound-modified mortar for tunnel grouting, Electronic J. of Geotechnical Engineering, 21(4), 1365-1374, (2016)

[18] A. Parghi and M. Shahria Alam, Effects of curing regimes on the mechanical properties and durability of polymer-modified mortars- an experimental investigation, J. of Sustainable Cement-Based Materials, 5(5), 324 - 347, (2016)

[19] V. Bhikshma, K. Jagannadha Rao and B. Balaji, An experimental study on behavior of polymer cement concrete, Asian J. of Civil Engineering (Building and Housing), 11(5), 563-573, (2010)

[20] E. Oussama, G. Elhem, M. Valerie and B.O. Mongi, Mechanical and physical properties of epoxy polymer concrete after exposure to temperatures up to $250^{\circ} \mathrm{C}$, Construction and Building Materials, 27(1), 415-424, (2012)

[21] M. Golestaneh, G. Amini, G.D. Najafpour and M.A. Beygi, Evaluation of mechanical strength of epoxy polymer concrete with silica powder as filler, World Applied Sciences J., 9(2), 216-220, (2010)

[22] R. Wang, P. Wang and X. Li, Physical and mechanical properties of styrene-butadine rubber emulsion modified cement mortars, Cement and Concrete Research, 35(5), 900 906, (2005)

[23] R. Bedi, R. Chandra and S. P. Singh, Mechanical properties of polymer concrete, J. of Composites, 2013, 1-12. (2013)

[24] K.T. Varughese and B.K. Chaturvedi, Fly Ash as fine aggregate in polyester based polymer concrete, Cement and Concrete Composites, 18(2), 105-108, (1996)

[25] J.P. Gorninski, D.C. Dal Molin and C.S. Kazmierczak, Study on the modulus of elasticity of polymer concrete compounds and comparative assessment of polymer concrete and portland cement concrete, Cement and Concrete Research, 34(11), 20912095, (2004) 
[26] H. Abdel-Fattah and M.M. El-Hawary, Flexural behavior of polymer concrete, Construction and Building Material, 13(5), 253-262, (1999)

[27] M.V.N. Sivakumar, Effect of polymer modification on mechanical and structural properties of concrete - an experimental investigation, Int. J. of Civil and Structural Engineering, 1(4), 732-740, (2010)

[28] L. Bureau, A. Alliche, Ph. Pilvin and S. Pascal, Mechanical characterization of a styrene-butadine modified mortar, Materials Science and Engineering: A, 308(1-2), 233-240, (2001)

[29] S. Pascal, A. Alliche and Ph. Pilvin, Mechanical behaviour of polymer modified mortars, Materials Science and Engineering: A, 380(1-2), 1-8, (2004)

[30] Z. Yang, X. Shi, A. T. Creighton and M. M. Peterson, Effect of styrene-butadine rubber latex on the chloride permeability and microstructure of portland cement mortar, Construction and Building Materials, 23, 2283-2290, (2009)

[31] F.A. Shaker, A.S. El-Dieb and M.M. Reda, Durability of styrene-butadine latex modified concrete, Cement and Concrete Research, 27(5), 711-720, (1997)

[32] D.A. Silva, H.R. Roman and P.J.P. Gleize, Evidences of chemical interaction between eva and hydrating portland cement, Cement and Concrete Research, 32, 1383-1390, (2002)

[33] H. Zhu, P. Wang, R. Wang and G.Zhang, Effects of two redispersible polymer powders on efflorescence of portland cement-based decorative mortar, Materials Science (Medziagotyra), 20(3), 345-350, (2014)

[34] L.R. Brancher, M.F. de Onunes, A.M.C. Grisa, D.T. Pagnussat and M. Zeni, Acoustic behavior of subfloor lightweight mortars containing micronized poly (Ethylene Vinyl Acetate) (EVA), Materials, 9(51), 1-9, (2016)

[35] M. Barbuta, M. Rujanu and A.Nicuta, Characterization of polymer concrete with different wastes additions, Procedia Technology, 22, 407-412, (2016)

[36] E. Aminudin, M.F. Md Din, M.W. Hussin, A H. Abdullah, K. Iwao and Y. Ichikawa, Properties of agro-Industrial aerated concrete as potential thermal insulation for building, MATEC Web of Conferences, 47, 1-9, (2016)

[37] M. A. Kumar and J. A. Bari, Flexural behaviour of polymer modified basalt fiber reinforced concrete - A review, Int. J. on Applications in Civil and Environmental Engineering, 1(3), 1-5, (2015)

[38] A.S. Momtazi, R.K. Khoshkbijari and S.S. Mogharab, Polymers in concrete: applications and specifications, Special Issue on New Trends in Architecture, Civil Engineering, and Urban Studies, European Online J. of Natural and Social Sciences, 3(3), 62-72, (2015)

[39] R.M.I. Retno Susilorini, H. Hardjasaputra, S. Tudjono, G. Hapsari, S,R. Wahyu, G. Hadikusumo and J. Sucipto, The advantage of natural polymer modified mortar with seaweed: green construction material innovation for sustainable concrete, Procedia Engineering, 95, 419-425, (2014)

[40] C. Niveditha, K. Sarayu, A. Ramachandra Murthy, V. Ramesh Kumar and R.I. Nagesh, Marine algae for cement mortar strengthening, J. of Civil Engineering Research, 4(2A), 23-25, (2014)

[41] Y.H. Jang, S.O. Han, I.N. Sim and H. Kim, Pretreatment effects of seaweed on the thermal and mechanical properties of seaweed/polypropylene biocomposites, Composites Part A: Applied Science and Manufacturing, 47, 83-90, (2013) 